\title{
Development and Validation of a Multivariate Calibration Model for Determination of Dipyrone in Oral Solutions by Near Infrared Spectroscopy
}

\author{
Marcus H. Ferreira, ${ }^{a}$ Jorge F. F. Gomes ${ }^{a}$ and Marcelo M. Sena ${ }^{*, b}$ \\ ${ }^{a}$ Indústria Química do Estado de Goiás SA, IQUEGO, 74450-010 Goiânia-GO, Brazil \\ ${ }^{b}$ Unidade Universitária de Ciências Exatas e Tecnológicas, Universidade Estadual de Goiás, \\ CP 459, 75000-000 Anápolis-GO, Brazil
}

\begin{abstract}
Este trabalho propôs um novo método para a determinação de dipirona (DIP) em soluções orais farmacêuticas, usando medidas de transflectância no infravermelho próximo (NIR) e calibração multivariada. A faixa de estudo foi de 300,0 a 569,2 $\mathrm{mg} \mathrm{mL}^{-1}$ de DIP. O melhor modelo PLS foi obtido com 2 variáveis latentes e apresentou erros médios quadráticos de calibração e de previsão (RMSEC e RMSEP) iguais a 1,1 e $1,0 \mathrm{mg} \mathrm{mL}^{-1}$, respectivamente. O método foi validado de acordo com as resoluções da ANVISA e do ICH e foi considerado seletivo, linear, preciso, exato e robusto. Em comparação com as principais alternativas, titulação iodimétrica e CLAE, este método é mais simples, não-destrutivo, não gasta reagentes ou solventes nem gera resíduos. Além disso, a maior vantagem está na rapidez da análise, pois são gastos cerca de $50 \mathrm{~s}$.
\end{abstract}

This work developed a new method for determination of dipyrone (DIP) in oral pharmaceutical formulations, through the use of near infrared (NIR) transflectance measurements and multivariate calibration. The studied range varied from 300.0 to $569.2 \mathrm{mg} \mathrm{mL}^{-1}$. The best PLS (partial least squares) model was obtained with two latent variables and the root mean square errors of calibration and prediction were 1.1 and $1.0 \mathrm{mg} \mathrm{mL}^{-1}$, respectively. The proposed method was validated in accordance with ANVISA, the Brazilian regulatory agency, and ICH, being considered selective, linear, precise, accurate and robust. By comparison with the main alternatives, iodimetric titration and HPLC, this method is simpler, non-destructive, does not use reagents or solvents and does not produce chemical waste. Besides, its rapidity is considered the major advantage over the other methods, since only about $50 \mathrm{~s}$ were spent per assay.

Keywords: multivariate calibration, quality control, PLS, metamizole, near infrared spectroscopy

\section{Introduction}

Dipyrone (DIP), the sodium salt of [(2,3-dihydro-1,5dimethyl-3-oxo-2-phenyl-1H-pyrazol-4yl)methylamino] methanesulfonic acid and also known as methamizole, is a non steroidal anti-inflammatory drug (NSAID) used as analgesic, antipyretic and antispasmodic. Since its introduction in the pharmaceutical market almost one hundred years ago, it has been one of the most consumed drugs in the word. The association of DIP administration with adverse effects, mainly the increased risk of agranulocytosis, ${ }^{1}$ is controversial and has led to its banishment in more than ten countries, such as United States, Australian, Denmark, Norwegian and

\footnotetext{
*e-mail: marcsen@ueg.br
}

Venezuela. In Brazil, in spite of restrictions on the sales for some formulations based on DIP, ${ }^{2}$ it has continued to be one of the most consumed analgesics. Brazilian ${ }^{3}$ and European ${ }^{4}$ Pharmacopoeias prescribe iodimetric titration for DIP determination, which is the most frequently method used in Brazilian pharmaceutical industry for the DIP quality control. However, this method has the drawbacks of low precision, long time of analysis and needing of cooling in iced water aiming to avoid loss of iodine by volatizalion. DIP has also been determined in pharmaceutical formulations by HPLC,, $45 \mathrm{UV}$-Visible spectrophotometry, ${ }^{6-10}$ turbidimetry, ${ }^{11}$ chemilumimetry, ${ }^{12,13}$ amperometry ${ }^{14}$ and voltammetry. ${ }^{15,16}$ The most of these methods involve cumbersome steps, such as derivatization reactions, previous separations, solvent extraction, or sample filtration. 
Nowadays, the great majority of analytical methods for quality control of pharmaceutical products are based on HPLC and univariate determinations. Although these methods are well established and recognized by regulatory agencies, they present the disadvantages of relative high cost and time consumption, spending substantial amounts of solvents and producing chemical waste. In the last years, near infrared spectroscopy (NIRS) ${ }^{17-19}$ has become a promising alternative for developing simple and reliable methods, which provide accurate and precise results with less human intervention. Methods based on NIRS are rapid, non-destructive and of wide application, allowing direct recording of spectra for solid and liquid forms with little or no sample pre-treatment. These advantages have turned NIRS attractive for the determination of active pharmaceutical ingredients in recent years. ${ }^{20-24}$ The key point for this growing popularity has been its combination with chemometric methodologies of multivariate calibration, since the complex nature of the NIR region seldom permits the use of single wavelength models for quantitative purposes.

Among the methods used for recording NIR spectra, the transflectance mode is one suitable alternative for the analysis of liquid and semi-solid samples..$^{17,20}$ This measurement mode, frequent when optical bundle probes are employed, was used in this work. In it, the incident light crosses the sample, is reflected off a piece of material such as stainless steel, gold or PTFE located on the opposite side, and travels back through the sample before reaching the detector. Thus, the optical path is twice as long as the distance between the entry point and the reflector.

Although pharmacopoeias have adopted some NIR spectroscopic methods for the identification of pharmaceuticals, this technique has not yet been officially endorsed for quantitative analysis. Considering the increasing regulatory pressure faced by the pharmaceutical industry to optimize quality control, a key aspect necessary for a wider acceptance of multivariate NIRS methods is the analytical validation. In Brazil, this aspect is regulated by ANVISA (National Agency of Sanitary Vigilance), which published a specific resolution for validation of analytical and bioanalytical methods in 2003. ${ }^{25}$ This resolution is based on the guidelines of International Conference on Harmonisation (ICH). ${ }^{26,27}$ The objective of this work was the development of a simple method for direct determination of DIP in oral pharmaceutical solutions, based on transflectance measurements on NIR region and multivariate calibration with partial least squares (PLS).$^{28}$ The method was validated for using in routine analysis in accordance with ANVISA guidelines.

\section{Experimental}

\section{Apparatus and software}

NIR spectra were recorded on a Foss NIRSystems 4500 Smart Probe Analyzer spectrophotometer (Silver Spring, USA), equipped with a transflectance probe. The reference signal employed for absorbance calculus is obtained from a measure of the empty cell closed to light. The instrument was controlled and data were acquired using the Vision 3.3.0.0 software package, also from Foss. Data were handled using MATLAB software, 6.5 version (The MathWorks, Natick, USA). PLS routine came from "PLS Toolbox", 3.5 version (Eigenvector Technologies, Manson, USA).

\section{Materials, reagents and solutions}

The analyzed oral solution formulation has the following composition per $\mathrm{mL}: 500 \mathrm{mg}$ of sodic DIP, $0.1 \mathrm{mg}$ of disodic EDTA, $0.1 \mathrm{mg}$ of sodium metabisulfite, $100 \mathrm{mg}$ of sorbitol $70 \%$ and deionized water. All the solutions were prepared with deionized water from a Millipore Milli-Q system (Bedford, USA). All chemicals were of analytical grade and used without further purification. Sodic DIP was purchased from Shandong Xinhua Pharm. Co. (Zibo, China) and standardized by iodimetry. ${ }^{4,5}$ Two stock solutions, both of $569.2 \mathrm{mg} \mathrm{mL}^{-1}$ DIP, were prepared in $2000 \mathrm{~mL}$ volumetric flasks containing appropriate amounts of excipients. These solutions were mixed, bubbled with nitrogen and filtered through cotton. Then, they were diluted accordingly in $50 \mathrm{~mL}$ volumetric flasks for the preparation of working solutions from 300.0 to $569.2 \mathrm{mg} \mathrm{mL}^{-1}$ (calibration and validation sets). Blank (placebo) solutions containing only the excipients were also prepared.

\section{Methodology}

The working solutions were placed in polyethylene flasks of about $50 \mathrm{~mL}$ and spectra were recorded by immersing the transflectance probe. Each spectrum was the average of 32 scans, obtained from 1100 to $2500 \mathrm{~nm}$ (step $2 \mathrm{~nm}$ ), with an optical path of $2 \mathrm{~mm}$. During the measurements, the temperature of the room was maintained at $25^{\circ} \mathrm{C}$.

For the analytical validation, the following figures of merit were estimated: selectivity, linearity, repeatability, intermediate precision, accuracy, robustness, range, limits of detection and quantification, sensitivity and analytical sensitivity. Spectra of ten samples of DIP pharmaceutical preparations produced by IQUEGO (production samples) were recorded for developing a spectral library used for 
selectivity evaluation. Six replicates of $500.0 \mathrm{mg} \mathrm{mL}^{-1}$ DIP solution were obtained for precision studies and the analyses were repeated at three different days with three different analysts for intermediate precision evaluation. Triplicates of 400.0, 500.0 and $569.2 \mathrm{mg} \mathrm{mL}^{-1}$ DIP solutions were obtained for the accuracy study. Robustness was evaluated by varying two conditions, the content of sorbitol and the room temperature. In the first essay, the interference of sorbitol was evaluated by measuring triplicates of a $490.0 \mathrm{mg} \mathrm{mL}^{-1}$ DIP solution containing three different levels of this excipient: the standard content $(100 \mathrm{mg})$, less $5 \%$ and more 5\%. In the second essay, triplicates of another $490.0 \mathrm{mg} \mathrm{mL}^{-1}$ DIP solution were measured at 20, 25 and $30{ }^{\circ} \mathrm{C}$. For the estimation of instrumental noise, fifteen spectra of a blank solution were recorded in the sequence. For comparison purposes, a diffuse reflectance spectrum of a pure solid sample of sodic DIP was recorded using an appropriate accessory. Finally, the obtained multivariate calibration model was applied in the determination of samples of three batches of a DIP pharmaceutical formulation produced by IQUEGO (Goiânia, Brazil). These samples were also analyzed by iodimetry, the official method of the Brazilian Pharmacopoeia. ${ }^{3}$ These determinations were performed in triplicate.

\section{Results and Discussion}

Transflectance NIR spectra were originally recorded between 1100 and $2500 \mathrm{~nm}$. A strong and broad absorption band above about $1900 \mathrm{~nm}$ was observed and attributed to $\mathrm{O}-\mathrm{H}$ bond from water. Thus, it was decided to eliminate this region and to restrict the model to the region between 1100 and $1884 \mathrm{~nm}$. Local models selecting parts of this wavelength region were also tried, but the best model was obtained for this whole region.

Since it was not feasible to obtain transflectance spectra of pure DIP, a diffuse reflectance spectrum of a solid sample of DIP was recorded for peak attribution purposes (Figure 1). Reflectance spectra, though not identical to the corresponding absorption ones, are similar in shape and provide the same chemical information. ${ }^{17}$ By observing Figure 1, it was possible to attribute the band between 1100 and $1250 \mathrm{~nm}$ to the second overtone and the combination of $\mathrm{C}-\mathrm{H}$ bonds, the bands between 1250 and $1550 \mathrm{~nm}$ to the first overtone and the combination of $\mathrm{C}-\mathrm{H}$ bonds, and the peak at $1675 \mathrm{~nm}$ to the first overtone of $\mathrm{C}-\mathrm{H}$ bonds. ${ }^{29}$

The DIP content of the oral formulations must be between 95 and $105 \%$ of the value specified by the manufacturer. ${ }^{3}$ Fifty one samples were prepared in the range from 300.0 to $569.2 \mathrm{mg} \mathrm{mL}^{-1}$. The upper limit was adopted because it was not possible to dissolve more DIP in the conditions of

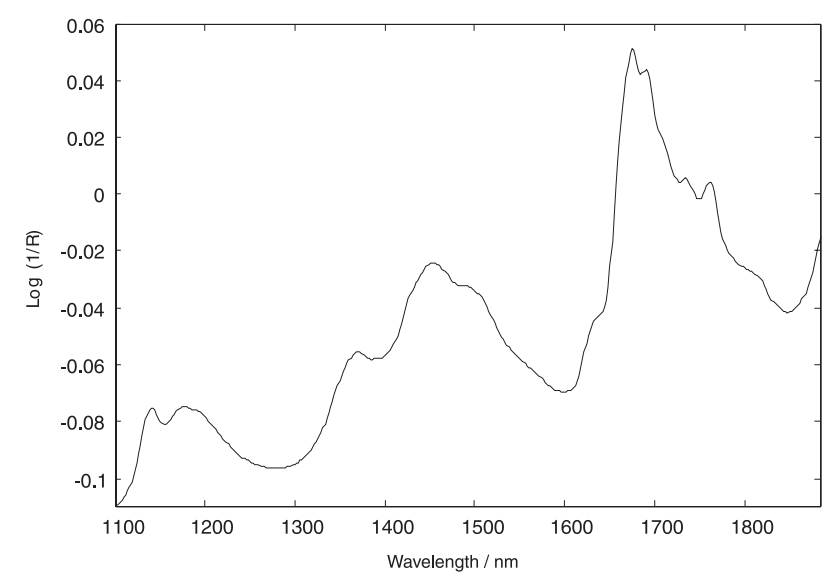

Figure 1. Diffuse reflectance spectrum of a DIP solid sample recorded from 1100 to $1884 \mathrm{~nm}$.

the analysis. The spectra are showed in Figure 2 and the calibration ones were correlated with reference values of DIP concentration as dependent variables through PLS regression. Thirty six solutions were chosen for the calibration set, in accordance with ASTM guidelines, ${ }^{30}$ and the remaining fifteen samples were used for the validation set. The best PLS model was selected with two latent variables and using only mean centering as data pre-treatment, accounting for 94.41 and $99.97 \%$ of the data variance in $\mathrm{X}$ and $\mathrm{Y}$ blocks, respectively. The use of first and second derivates and multivariate scattering correction (MSC) were tried, but PLS models presented higher errors. This is coherent with the observed absence of baseline deviations and drifts in the obtained spectra. Root mean square errors of calibration (RMSEC) and prediction (RMSEP) were calculated as $1.1 \mathrm{mg} \mathrm{mL}^{-1}(0.22 \%)$ and $1.0 \mathrm{mg} \mathrm{mL}^{-1}(0.20 \%)$, respectively.

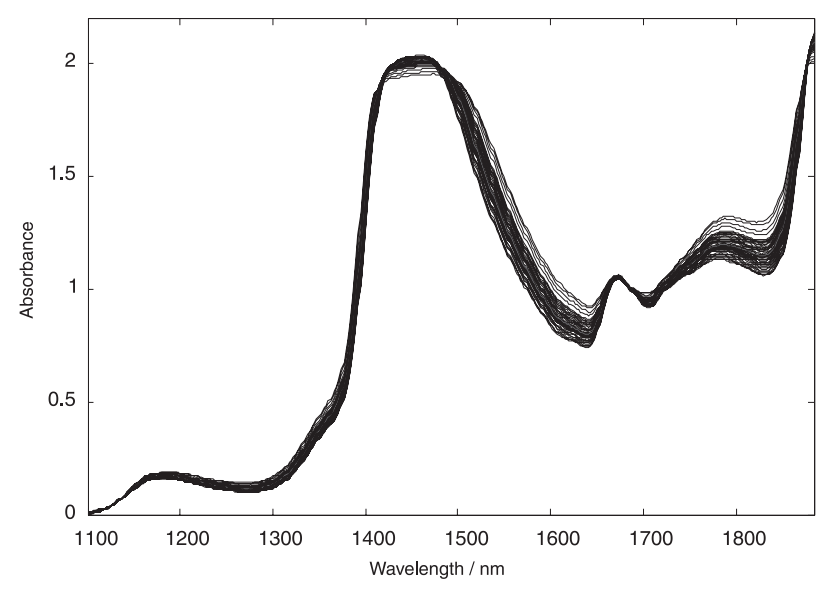

Figure 2. Spectra of fifty one DIP samples, corresponding to the calibration and the validation sets. The spectra are mean centered.

By observing Figure 2, it is possible to note a spectral region between 1710 to $1820 \mathrm{~nm}$, which could be attributed only to the active principle. Therefore, univariate calibration 
models using only one wavelength from this region were previously tested. Several wavelengths were tried and the best univariate model was obtained at $1790 \mathrm{~nm}$, but the errors of prediction were about eight times larger than the ones obtained by the selected multivariate model. In addition, the obtained correlation coefficient was 0.98 , lower than 0.99 , the minimum value officially accepted. ${ }^{25}$ Thus, the use of a more complex multivariate model is justified.

\section{Analytical validation}

The determination of figures of merit (FOM) is a fundamental requisite for the validation of multivariate methods, aiming at their acceptance by regulatory agencies in the future and, consequently, their wider application. ${ }^{31,32}$ The proposed NIR method was validated in accordance with ANVISA ${ }^{25}$ and ICH $^{26,27}$ guidelines. Selectivity, linearity, repeatability, intermediate precision, accuracy, robustness and range were estimated as required by ANVISA. Though not necessary for the official validation of this method, limits of detection and quantification, sensitivity and analytical sensitivity were also estimated.

\section{Selectivity}

The terms selectivity and specificity are considered synonymous by ANVISA ${ }^{25}$ and their meanings presented in the guidelines from regulatory agencies are conceived in a univariate way. In contradiction to this, this concept should be applied to multivariate methods in a different way, which remains a challenge for official recognition of this kind of methods, in particular NIRS based ones. In this work, selectivity was evaluated by two different ways.

The first one was based on the NIRS specific guidelines ${ }^{33}$ and was established by the use of spectral libraries which allow the identification of the pharmaceutical preparation as a combination of APIs and excipients, not to the analyte separated. The spectral library was developed containing spectra from ten production samples, which should encompass the normal variability of the productive process. The correlation coefficient was used as criterion and the threshold for positive identification of the pharmaceutical preparation was set at 0.98 , which allowed its identification as such and differentiation from interferences (excipients). ${ }^{24}$ The selectivity of the library was assessed with external samples not used in its development. All the production samples studied were positively identified and the main excipients (deionized water and sorbitol) and a placebo sample were correctly discriminated with identification values below the threshold. The correlation coefficient values provided by the library are shown in Table 1 .
The second way of evaluating selectivity was based on the application of the proposed multivariate model to predict triplicates of a placebo sample. ${ }^{23}$ Since these predictions, $51.0 \pm 2.9 \mathrm{mg} \mathrm{mL}^{-1}$, were far from the working range from 300.0 to $569.2 \mathrm{mg} \mathrm{mL}^{-1}$ of DIP, the method was considered selective in the presence of excipients.

Table 1. Selectivity. Identification of the pharmaceutical preparation and its excipients

\begin{tabular}{ll}
\hline Compound & Correlation coefficient \\
\hline Pharmaceutical preparation & 0.99 \\
Placebo preparation & 0.96 \\
Deionized water & 0.96 \\
Sorbitol 70\% & 0.91 \\
\hline
\end{tabular}

Threshold 0.98 (positive identification: Id results $>0.98$ ).

\section{Linearity}

For univariate methods, linearity is usually assessed from a signal versus concentration plot. Since multivariate methods do not allow this type of plot to be obtained, reference versus NIRS values plot is used instead. This plot for the proposed model in the range from 300.0 to $569.2 \mathrm{mg} \mathrm{mL}^{-1}$ of DIP, corresponding from 60.0 to $113.8 \%$ of the target DIP content in the analyzed formulation, is shown in Figure 3 and the obtained correlation coefficient was 0.9998 , confirming the linearity of the method.

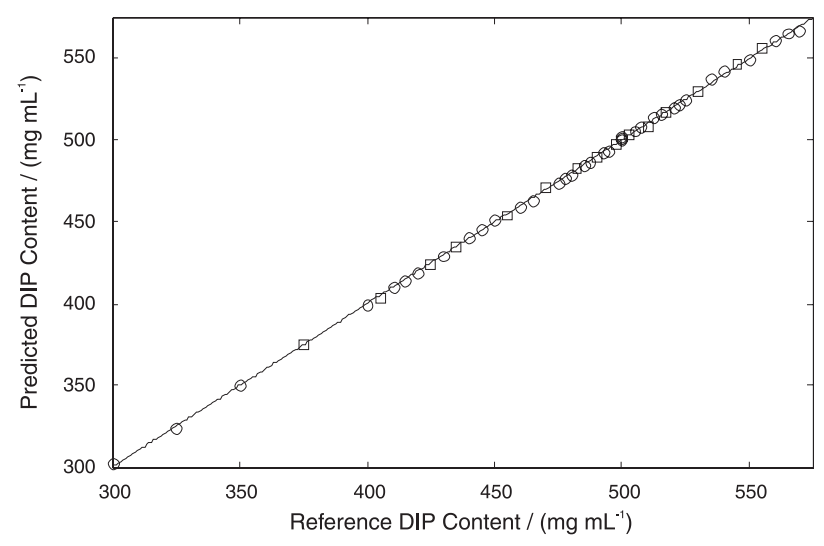

Figure 3. Linearity. Plot of reference versus predicted values. Calibration (circles) and validation (squares) samples.

\section{Precision}

The precision of the method was evaluated at two levels, repeatability and intermediate precision. Repeatability was assessed by the same analyst determining six replicates of a $500.0 \mathrm{mg} \mathrm{mL}^{-1}$ DIP solution on the same day. The obtained relative standard deviation (RSD) was $0.15 \%\left(0.8 \mathrm{mg} \mathrm{mL}^{-1}\right)$, 
much lower than the officially accepted 5\% for this type of determination. ${ }^{25}$

Intermediate precision was assessed by three different analysts determining six replicates of a $500.0 \mathrm{mg} \mathrm{mL}^{-1}$ DIP solution on three different days. The results are shown in Table 2 and the overall RSD was $0.44 \%\left(2.2 \mathrm{mg} \mathrm{mL}^{-1}\right)$, again much lower than $5 \%$.

Table 2. Evaluation of the intermediate precision for the proposed method, expressed through the RSD of six replicates of a $500.0 \mathrm{mg} \mathrm{mL}^{-1}$ DIP solution

\begin{tabular}{lc}
\hline Assay & RSD / (\%) \\
\hline Analyst 1/Fist day & 0.15 \\
Analyst 2/Second day & 0.75 \\
Analyst 3/Third day & 0.41 \\
\hline
\end{tabular}

\section{Accuracy}

In chemometrics, accuracy is usually expressed through the RMSEP estimation for an independent validation set. Nevertheless, this parameter is not considered by regulatory agencies and the accuracy of the proposed NIR method was estimated in accordance with official guidelines ${ }^{25,27}$ by applying it to nine synthetic mixtures, triplicates of three DIP concentrations, $400.0,500.0$ and $569.2 \mathrm{mg} \mathrm{mL}^{-1}$. The results are shown in Table 3 and the recovery varied between 99.4 and $100.8 \%$, assuring the accuracy of the method.

Table 3. Evaluation of the accuracy for the proposed method

\begin{tabular}{ccc}
\hline $\begin{array}{c}\text { Added DIP / } \\
\left(\mathrm{mg} \mathrm{mL}^{-1}\right)\end{array}$ & $\begin{array}{c}\text { Predicted DIP/ } \\
\left(\mathrm{mg} \mathrm{mL}^{-1}\right)\end{array}$ & $\begin{array}{c}\text { Recovery / } \\
(\%)\end{array}$ \\
\hline 400.0 & 399.9 & 100.0 \\
400.0 & 397.5 & 99.4 \\
400.0 & 403.3 & 100.8 \\
500.0 & 500.3 & 100.1 \\
500.0 & 501.4 & 100.3 \\
500.0 & 501.8 & 100.4 \\
569.2 & 566.9 & 99.6 \\
569.2 & 568.4 & 99.8 \\
569.2 & 566.0 & 99.4 \\
\hline
\end{tabular}

\section{Robustness}

The robustness was evaluated by varying two conditions. Firstly, the interference of the excipient sorbitol was evaluated. Triplicates of three samples of a $490.0 \mathrm{mg} \mathrm{mL}^{-1}$ DIP solution were prepared containing 95, 100 and $105 \mathrm{mg}$ of sorbitol, respectively. The results for these predictions are shown in Table 4 and non-paired t-tests demonstrated that there is no significant difference at $95 \%$ of confidence level. This result is important, because it indicates that the method is robust to a variation of $\pm 5 \%$ in the content of the main excipient. Since other excipients, such as EDTA and metabissulfite, are present in much less quantity, they might show no interference.

Secondly, the robustness was evaluated by comparing predictions for triplicates of another $490.0 \mathrm{mg} \mathrm{mL}^{-1} \mathrm{DIP}$ solution at three levels of controlled room temperature, 20, 25 and $30^{\circ} \mathrm{C}$. The results are shown in Table 5 and t-tests also demonstrated that there is no significant difference at $95 \%$ of confidence level. Thus, the method was considered robust in relation to small variations of temperature.

Table 4. Evaluation of the robustness of the proposed method through the determination of a $490.0 \mathrm{mg} \mathrm{mL}^{-1}$ DIP solution at three different levels of sorbitol, the main excipient

\begin{tabular}{lc}
\hline Sorbitol Content / mg & Predicted DIP / $\left(\mathrm{mg} \mathrm{mL}^{-1}\right)^{\mathrm{a}}$ \\
\hline 95 & $490.3 \pm 1.7$ \\
100 & $489.6 \pm 0.9$ \\
105 & $487.1 \pm 1.4$ \\
\hline
\end{tabular}

${ }^{\mathrm{a}}$ Mean values and standard deviations of three determinations.

Table 5. Evaluation of the robustness of the proposed method through the determination of a $490.0 \mathrm{mg} \mathrm{mL}^{-1}$ DIP solution at three different temperatures, 20,25 and $30^{\circ} \mathrm{C}$

\begin{tabular}{lc}
\hline Temperature $/\left({ }^{\circ} \mathrm{C}\right)$ & Predicted DIP / $\left(\mathrm{mg} \mathrm{mL}^{-1}\right)^{\mathrm{a}}$ \\
\hline 20 & $489.9 \pm 1.2$ \\
25 & $491.5 \pm 0.9$ \\
30 & $491.0 \pm 1.0$ \\
\hline
\end{tabular}

a Mean values and standard deviations of three determinations.

Range

Considering the linearity, precision and accuracy studies, the range of the method was established from 400.0 to $569.2 \mathrm{mg} \mathrm{mL}^{-1}$ of DIP.

\section{Limits of detection and quantitation}

According to official guidelines, ${ }^{25,26}$ the characteristics of the proposed method dispense with the need to determine their limits of detection (LOD) and quantitation (LOQ). Nevertheless, LOD and LOQ were estimated for this method. LOD can be calculated for multivariate methods as follows:

LOD = $3\|\boldsymbol{\varepsilon}\| /\|\mathbf{N A S}\|$ 
where the symbol "II II" means the Euclidean norm of a vector, $\boldsymbol{\varepsilon}$ contains the estimation of the instrumental noise from fifteen spectra of the blank, and NAS is the net analyte signal. This last term is defined as the part of the signal that is orthogonal to the signal of the interferences present in the sample. ${ }^{34}$ NAS is a vector containing values for each sample and can be related to the regression vector, b, from an inverse calibration model, such as PLS, by the following equation: ${ }^{35}$

$\|\mathbf{N A S}\|=1 /\|\mathbf{b}\|$

For this method, LOD was estimated as $1.0 \mathrm{mg} \mathrm{mL}^{-1}$.

Analogously, LOQ could be estimated as $10\|\boldsymbol{\varepsilon}\| /$ \|NAS |, but NIRS specific guidelines for the pharmaceutical industry ${ }^{33}$ indicate that is constrained by the lowest level available in the sample calibration set. Therefore, LOQ was estimated as $300.0 \mathrm{mg} \mathrm{mL}^{-1}$ for this method.

\section{Sensitivity and analytical sensitivity}

The sensitivity (SEN) of a multivariate method can be estimated as the NAS at unit concentration, ${ }^{31,32}$ according to equation 3. A more informative FOM is the analytical sensitivity $(\gamma)$, which is defined, in analogy with univariate calibration, ${ }^{36}$ as the ratio between SEN and the instrumental noise, as expressed in equation 4. The inverse of $\gamma$ is an estimate of the minimum concentration difference that is discernible by the analytical method in the absence of experimental error, independent of the specific technique employed.

SEN $=\|\mathbf{N A S}\|$

$\gamma=\operatorname{SEN} /\|\boldsymbol{\varepsilon}\|$

The calculated values of SEN and $\gamma$ were 0.01 and 3.05 , respectively. This $\gamma$ estimate means that the proposed method is able to discern a difference of $0.3 \mathrm{mg} \mathrm{mL}^{-1}$, corroborating its good quality.

\section{Analysis of real samples}

Three batches of an oral pharmaceutical formulation manufactured by IQUEGO were analyzed by the proposed method and the results are shown in Table 6, together with the results obtained by the official iodimetric titration method. ${ }^{3}$ A non-paired t-test with four degrees of freedom was used to compare the results of the two methods and the estimates show no significant difference at $95 \%$ confidence level. The observed standard deviations also showed that the proposed method is more precise than the official one, but its main advantage is the rapidity of the analysis: about $50 \mathrm{~s}$ per assay versus about $40 \mathrm{~min}$ per assay for iodimetry.

Table 6. Determination of DIP in three batches of an oral pharmaceutical formulation by the proposed NIRS-PLS method and by the official iodimetric titration method. The label claim of the formulation is $500.0 \mathrm{mg} \mathrm{mL}^{-1}$

\begin{tabular}{lcc}
\hline Batch number & Proposed method / $(\%)^{\mathrm{a}}$ & Official method / $(\%)^{\mathrm{a}}$ \\
\hline$\# 1$ & $489.6 \pm 0.8$ & $490.0 \pm 3.0$ \\
$\# 2$ & $501.7 \pm 1.3$ & $500.5 \pm 4.0$ \\
$\# 3$ & $491.9 \pm 1.0$ & $493.0 \pm 3.0$ \\
\hline
\end{tabular}

${ }^{a}$ Mean values and standard deviations of three determinations.

\section{Conclusions}

A NIR method was developed for direct determination of DIP in oral pharmaceutical formulations. The proposed method is much more rapid than the main alternatives, namely iodimetric titration and HPLC. Besides, it presented other advantages over these methods, such as a simplified analytical procedure with less human intervention, non-destructivity, no need for reagents or solvents and no production of chemical waste. In the future, this method could be applied to on line measurements. The NIR method was validated in accordance with ANVISA and ICH guidelines and was considered selective, linear, precise, accurate and robust, demonstrating the potential for future acceptance of this kind of method by regulatory agencies.

\section{References}

1. Danieli, P.; Leal, B. M.; Rev. Bras. Farm. 2003, 84, 17.

2. http://www7.anvisa.gov.br/divulga/noticias/2004/161204.htm, accessed in February 2007.

3. Farmacopéia Brasileira, 4a. ed., Ateneu Editora: São Paulo, Brasil, 2002.

4. European Pharmacopoeia, $4^{\text {th }}$ ed., Council of Europe: Strasbourg, 2002.

5. Senyuva, H. Z.; Aksahin, I.; Ozcan, S.; Kabasakal, B. V.; Anal. Chim. Acta 2005, 547, 73.

6. Pereira, A. V.; Penckowski, L.; Vosgerau, M.; Sassa, M. F.; Fatibello, O.; Quim. Nova 2002, 25, 553.

7. Lima, J. L. F. C.; Sá, S. M. O.; Santos, J. L. M.; Zagatto, E. A. G.; J. Pharm. Biomed. Anal. 2003, 32, 1011.

8. Marcolino, L. H.; Sousa, R. A.; Fatibello, O.; Moraes, F. C.; Teixeira, M. F. S.; Anal. Lett. 2005, 38, 2315.

9. do Nascimento, A. P.; Trevisan, M. G.; Kedor-Hackmann, E. R. M.; Poppi, R. J.; Anal. Lett. 2007, 40, 975. 
10. Weinert, P. L.; Pezza, L.; Pezza, H. R.; J. Braz. Chem. Soc 2007, 18, 846.

11. Marcolino, L. H.; Bonifacio, V. G.; Fatibello-Filho, O.; Teixeira, M. F. S.; Quim. Nova 2005, 28, 783.

12. Song, Z.; Zhang, N.; Talanta 2003, 60, 161.

13. Zhao, L. X.; Li, B. X.; Zhang, Z. J.; Lin, J. M.; Sens. Actuators, B 2004, 97, 266.

14. Munoz, R. A. A.; Matos, R. C.; Angnes, L.; J. Pharm. Sci. 2001, 90, 1972.

15. Teixeira, M. F. S.; Marcolino-Junior, L. H.; Fatibello-Filho, O.; Dockal, E. R.; Cavalheiro, E. T. G.; J. Braz. Chem. Soc. 2004, 15,803 .

16. Daniel, D.; Gutz, I. G. R.; Anal. Chim. Acta 2006, 571, 218.

17. Pasquini, C.; J. Braz. Chem. Soc. 2003, 14, 198.

18. Blanco, M.; Villarroya, I.; TrAC, Trends Anal. Chem. 2002, 21 , 240.

19. Burns, D. A.; Ciurczak, E. W.; Handbook of Near-Infrared Analysis, $2^{\text {nd }}$ ed., Taylor \& Francis: New York, 2001.

20. Blanco, M.; Romero, M. A.; J. Pharm. Biomed. Anal. 2002, 30, 467.

21. Dou, Y.; Sun, Y.; Ren, Y.; Ren, Y.; Anal. Chim. Acta 2005, 528, 55.

22. Freitas, M. P.; Sabadin, A.; Silva, L. M.; Giannotti, F. M.; do Couto, D. A.; Tonhi, E.; Medeiros, R. S.; Coco, G. L.; Russo, V. F. T.; Martins, J. A.; J. Pharm. Biomed. Anal. 2005, 39, 17.

23. Baratieri, S. C.; Barbosa, J. M.; Freitas, M. P.; Martins, J. A.; J. Pharm. Biomed. Anal. 2006, 40, 51

24. Blanco, M.; Alcalá, M.; Eur. J. Pharm. Sci. 2006, 27, 280.
25. Agência Nacional de Vigilância Sanitária (ANVISA); Guia para Validação de Métodos Analíticos e Bioanalíticos, Resolução-RE No. 899, Brasil, 2003.

26. International Conference on Harmonization; Tripartite Guideline-Q2A Text on Validation of Analytical Procedures, Fed. Regist., 60 FR 11260, USA, 1995.

27. International Conference on Harmonization; Tripartite Guideline-Q2B Validation of Analytical Procedures: Methodology, Fed. Regist., 62 FR 27464, USA, 1997.

28. Brereton, R. G.; Analyst 2000, 125, 2125.

29. Workman Jr., J. J.; Appl. Spectrosc. Rev. 1996, 31, 251.

30. Annual Book of ASTM Standards, Standard Practices for Infrared Multivariate Quantitative Analysis-E1655-00, ASTM International, West Conshohocken: Pennsylvania, USA, 2000.

31. Braga, J. W. B.; Poppi, R. J.; Quim. Nova 2004, 27, 1004.

32. Braga, J. W. B.; Poppi, R. J.; J. Pharm. Sci. 2004, 93, 2124.

33. Broad, N.; Graham, P.; Hailey, P.; Hardy, A.; Holland, S.; Hughes, S.; Lee, D.; Prebble, K.; Salton, N.; Warren, P. In Handbook of Vibrational Spectroscopy, Chalmers, J. M.; Griffiths, P. R., eds.; vol. 5, Wiley: Chichester, UK, 2002, p.

34. Lorber, A.; Faber, K.; Kowalski, B. R.; Anal. Chem. 1997, 69, 1620.

35. Booksh, K. S.; Kowalski, B. R.; Anal. Chem. 1994, 66, 782A.

36. Cuadros-Rodriguez, L.; García-Campaña, A. M.; JimenezLinares, C.; Román-Ceba, M.; Anal. Lett. 1993, 26, 1243.

Received: March 15, 2008

Web Release Date: September 18, 2009 